\title{
Depression symptoms and associated factors among thalassemia patients in the Palestinian Territories: a cross-sectional study
}

\author{
Adnan Lutfi Sarhan ${ }^{1 *} \mathbb{D}$, Shahenaz Modallal ${ }^{1,2,3}$, Fayez Azez Mahamid ${ }^{1,2,3}$ and Denise Ziya Berte ${ }^{1,2,3}$
}

\begin{abstract}
Background: Thalassemia is a condition that causes the human body to destroy red blood cells faster than they can be made. It causes physical symptomology as well as psychological distress. The current study aimed to identify the prevalence of depression symptoms among individuals with moderate to severe thalassemia. A quantitative descriptive cross-sectional design was applied utilizing the Beck Depression Inventory to assess the level of depression in the sample.
\end{abstract}

Results: Some significant relationships were demonstrated in the sample: males reporting severe depression symptoms than females by 6.0 times $(95 \% \mathrm{Cl} 0.07-0.62, p 0.014)$, and reporting moderate depression symptoms $(95 \% \mathrm{Cl}$ $0.00-0.47, p 0.05$ ). Additionally, income was found to be a predictor of level of depression symptoms with low income reported higher incidence of severe depression symptoms than those whose monthly income was $>400 \$$ by 18.4 times (95\% Cl 0.38-1.03, $p \leq 0.001$ ), but not reporting a significant association between moderate depressive symptoms and monthly income ( $95 \% \mathrm{Cl}-012-1.47$, P 0.225). A significant association was found between the educational attainment and level of depression symptoms with lower levels of education predicting higher levels of severe depression symptoms ( $95 \% \mathrm{Cl} 0.069-0.89, p 0.022$ ), but no significant association was reported between moderate depression symptoms and educational attainment ( $95 \% \mathrm{Cl}-0.49-0.01, p 0.81)$.

Related to disease characteristics a relationship was confirmed between severe depressive symptoms and medication level such as the individual needing tablets or pumps (95\% Cl 0.189-1.05, $p 0.005$ and $95 \% \mathrm{Cl} 0.52-1.44, p 0.001$ ) respectively. Other disease related variables showed no significant correlation with depressive symptom levels. Additional significant relationships were found in environment whereas increased moderate depressive symptoms were experienced by individuals residing in rural areas as opposed to those living in IDP camps or cities by 4 times ( $95 \% \mathrm{Cl}-0.30-0.01, p 0.04)$, but no significant association was found between severe depression and the place of residence. The other independent variables had no significant correlation with severe or moderate depressive symptoms.

\footnotetext{
*Correspondence: asarhan@najah.edu

${ }^{1}$ Faculty of Medicine and Health Sciences, Department of Biomedical

Sciences, Public Health Division, An-Najah National University, P.O. Box 7,

Nablus, Palestine

Full list of author information is available at the end of the article
} 
Conclusion: In light of these findings addressing symptoms of depression directly and supporting patients with thalassemia with basic life needs unrelated to their disease maybe mitigating depressive symptoms which may negatively affect recovery.

Keywords: Thalassemia, Depression, Palestine

\section{Background}

Thalassemia is a set of genetic diseases of hemoglobin synthesis characterized by reduced or absence of one or more of a person's hemoglobin [1]. Thalassemia is globally the most common genetic disease related to a chronic blood disorder. Characterized medically by decreased synthesis of one of the two types of polypeptide (chain B and A) that form the adult human hemoglobin molecule. It reduces the filling of the red blood cells with hemoglobin and leads to anemia [2].

There are two kinds of thalassemia; the first is alphathalassemia, commonly found in individuals from the Middle East, Southeast Asia, China, and Africa. There are an estimated 26 million alpha-thalassemia carriers of Southeast Asian origin, 5-15\% of Alpha-thalassemia occurs in the Mediterranean area (Cyprus, Turkey, Greece, and Southern Italy) and approximately $1 \%$ in the Middle East [3].

The second strand designated as beta-thalassemia, is a complex disease most common in Africa, the Mediterranean region, China, the Middle East, the Indian Subcontinent, and Southeast Asia, stretching from Southern China down the Malaysian Peninsula to the Indonesian Islands [4]. In beta-thalassemia intermediate (TI) the deficiency of beta protein in the hemoglobin causes moderate to severe anemia, causing complications, including bone deformities and enlargement of the spleen [5].

Thalassemia major (TM) also known as Cooley's anemia or beta-thalassemia, occurs when the gene abnormalities affect the production of the beta-globin protein. It is the most common and dangerous type of beta-thalassemia as it damages beta protein in the hemoglobin chain, leading to life-threatening anemia. In the case of major thalassemia, the individual is likely to require recurrent blood transfusions and prolonged medical care. The treatments themselves often lead to iron overload, which is remediated with chelation therapy to prevent early complications that end with the loss of life due to organ failure [6].

Physical symptoms can differ significantly depending on the form of thalassemia and the seriousness of the condition that the individual suffers from. Individuals with thalassemia may complain of irritability, pale appearance, weakness and fatigue, facial bone deformities, discoloration of the skin, and shortness of breath [7].
The total number of thalassemia patients in Palestine is about 866, of whom are 557 in West Bank and 309 in Gaza Strip [8]. Depression is the most common psychological complication for individuals with thalassemia [9]. The prevalence of depression in patients with thalassemia has been estimated to be between $8-12 \%$ among adult men and 20-25\% among adult women [10]. These findings are significantly higher than the general prevalence of depression which was estimated to be between 2 and $9 \%$ with the incidence of depression found to be higher among females than males: 2:1 in the general population [11].

Individuals with thalassemia are exposed to emotional higher levels of distress related to their symptoms that may affect self-esteem negatively across the life span as children, adolescents, and adults [5].

Yahia et al. (2013) conducted a study evaluated the prevalence of anxiety and depression among individuals affected by thalassemia in Egypt, the study indicated that $32.1 \%$ and $16.1 \%$, of patients reported experiencing clinical and borderline levels of depression. The physical symptoms related to depression were heart failure, frequent hospitalization, diabetes mellitus, short stature, and delayed puberty [12].

Also, Maheri et al (2018) conducted a study in Iran using the hospital anxiety and depression scale to investigate anxiety and depression among patients with thalassemia, they found $19.8 \%$ had depression and $23.7 \%$ had an anxiety disorder [13].

A longitudinal study done by the American Clinical Research Network for thalassemia investigated the symptoms of depression and anxiety in patients with thalassemia, found that $11 \%$ of the patients had symptoms of depression [14].

The explanation of relative hypercholesterolemia in beta-thalassemia patients is the result of accelerated erythropoiesis and increased low-density lipoprotein (LDL) uptake by macrophages of reticuloendothelial system [15]. The hypercholesterolemia decreases the atherosclerosis but also has negative consequences especially major depression [16].

The current study investigating the level of depression symptoms among patients with thalassemia in the West Bank of Palestinian territories. This study is necessary to explore the psychological effect of such thalassemia trait among the Palestinian population. 


\section{Methods}

\section{Study design}

A descriptive cross-sectional design was used to achieve the aims and the objectives of the current study. The study population were patients with thalassemia (moderate to severe) who were admitted for regular blood transfusion treatment.

\section{Setting}

The patients were recruited from five government hospitals in the West Bank of Palestine; Al-Watani in the city of Nablus, Darwish Nazal in the city of Qalqilia, Dr. Thabet Thabet Hospital in the city of Tulkarm, Jenin Hospital in the city of Jenin, and Tubas Hospital in the city of Tubas.

The sample size for this study was calculated based on $95 \% \mathrm{CI}$ and $5 \%$ margin of error by using the Raosoft software sample size calculator and the recommended sample was 163 individuals aged (16-26) with moderate and severe thalassemia, and excluded more age categories because the life rate for thalassemia patients is $25-30$ years. Any patient has thalassemia, from the mentioned districts, not diagnosed with psychiatric disorders; was included. Of these patients with thalassemia, 41 were from Tulkarm (29 TM and $12 \mathrm{TI}$ ), 30 from Qalqilia (20 TM and $10 \mathrm{TI}, 40$ from Nablus (30 TM and $10 \mathrm{TI}$ ), 48 from Jenin (40 TM and $8 \mathrm{TI}$ ), and four from Tubas (1 TM and $3 \mathrm{TI}$ ). The sample was conveniently chosen between 2018 and 2019. The sample size applied was based on and according to similar studies.

\section{Data collection}

All participants completed a recruitment survey in a closed area inside the hospital. Data was collected through face-to-face interviews with all the participants who agreed and who met the inclusion criteria. Each interview lasted approximately 10 to $15 \mathrm{~min}$.

\section{Measures}

Beck Depression Inventory (BDI): The BDI is selfreported instrument that consists of 21 questions on a Likert scale. Scores 1-13 indicate minimal depressive symptoms, 14-19 mild depressive symptoms, 20-28 having moderate depression, and 29-63 suggests that the individual has severe depression. The validity of the BDI has been applied in multiple cultural settings several researchers worldwide $[17,18]$.

Alansari (2006) examined the Arabic BDI version against validity and reliability of the tool in Arabic culture, was found to be valid, Cronbach alpha coefficient indicated high level of internal consistency $(\alpha=0.85)$ [19]. In the current study, we used Alansari validated, reliable, and Arabic version.

\section{Statistical analysis}

The data were analyzed using IBM SPSS software ver. 21.0 through descriptive statistics (mean, standard deviation, frequency, and percentage) and analytical statistics using generalized linear regression model. The results were considered to be significant at the conventional level of $P \leq 0.05$. The minimal to mild depression variable considered in this study as a referral factor when analyzed the regression, due to that all thalassemia patients had at least minimal to mild depression and there was no one free from depression

symptoms.

\section{Results}

Results of demographic information in Table 1 shows that the female participants outnumbered the male participants: $55.2 \%$ versus $44.8 \%$. $38.7 \%$ of participants were

Table 1 Distribution of the participants according to socio-demographic data

\begin{tabular}{|c|c|c|c|c|c|}
\hline Variables & & No\% & Variable & & No\% \\
\hline \multirow[t]{2}{*}{ Gender } & Male & $(73) 44.8$ & Age at diagnosis & $\leq 1$ year & $(105) 65$ \\
\hline & Female & $(90) 55.2$ & & $\geq 1$ year & $(58) 35$ \\
\hline \multirow[t]{3}{*}{ Age } & $16-20$ & $(43) 26.3$ & Transfusion Frequency & Weekly & $(45) 27.6$ \\
\hline & $21-25$ & $(63) 38.7$ & & Monthly or more & $(118) 72.4$ \\
\hline & $>25$ & $(57) 35.0$ & Percentage of Ferritin & Low & $(62) 38.0$ \\
\hline \multirow[t]{3}{*}{ Residency } & IDP camp & $(27) 16.5$ & & High & $(101) 62.0$ \\
\hline & Rural village & (95)58.3 & Medication for the treat- & Tablet & (97)59.5 \\
\hline & City & $(41) 25.2$ & ment of Ferritin & Pump machine & $(48) 29.5$ \\
\hline \multirow[t]{3}{*}{ Education levels } & Primary & $(22) 13.5$ & & No treatment & $(18) 11.0$ \\
\hline & Secondary & $(67) 41.1$ & Complications & Change of face shape & $(22) 13.5$ \\
\hline & Diploma and higher & (74) 45.4 & & Splenomegaly and Hepatomegaly & $(141) 86.5$ \\
\hline
\end{tabular}


older than 20 years old. Most of the participants (58.3\%) were from rural villages (as opposed to cities or internally displaced people's camps (IDP)). About $41 \%$ of the participants had completed high school. Sixty-five percent of the participants were diagnosed with thalassemia at the age of $\leq 1$, while $35 \%$ were diagnosed after 1 year of age.

Regarding transfusion frequency, the results showed that $72.4 \%$ of the sample received blood transfusion monthly and above, while $27.6 \%$ received blood transfusion weekly. About $62 \%$ of the sample had a high ferritin level; which reflects the vulnerability to develop iron overload related complication, close to $60 \%$ of participants used tablets to treat ferritin, while $29.5 \%$ used pump machines, and $11 \%$ did not need treatment. Also, $86.5 \%$ of the participants reported complications such as hepatomegaly, splenomegaly, and heart failure, 13.5\% who said facial disfiguration.

As Table 2 shows, $55.8 \%$ of the sample reported severe level of depression, $22.8 \%$ experienced moderate depression, $15.3 \%$ had minimal depression, and $6.1 \%$ suffered from mild depression.

Results of Table 3 illustrates the significant correlation between level of depressive symptoms related to demographic and disease characteristics/effects in the sample. The results demonstrate a significant association between gender and depression symptoms with males reporting severe depression symptoms than females by 6.0 times (95\% CI $0.07-0.62, p$ 0.014), and reporting moderate depression symptoms (95\% CI $0.00-0.47, p$ 0.05). Additionally, income was found to be a predictor of level of depression symptoms with low income (individuals with monthly income of < 400\$; the minimum wage in Palestine) reported higher incidence of severe depression symptoms than those whose monthly income was $>400 \$$ by 18.4 times $(95 \%$ CI $0.38-1.03, p \leq 0.001)$, but not reporting a significant association between moderate depressive symptoms and monthly income (95\% CI 012-1.47, P 0.225).

A significant association was found between the educational attainment and level of depression symptoms with lower levels of education predicting higher levels of severe depression (95\% CI 0.069-0.89, $p$ 0.022), but no

Table 2 Distribution of the sample according to the depression level

\begin{tabular}{ll}
\hline Level & Frequency (\%) \\
\hline Minimal & $25(15.3)$ \\
Mild & $10(6.1)$ \\
Moderate & $37(22.8)$ \\
Severe & $91(55.8)$ \\
Total & $163(100)$ \\
\hline
\end{tabular}

significant association was reported between moderate depression symptoms and educational attainment (95\% CI - 0.49-0.01, $p$ 0.81).

Related to disease characteristics a relationship was confirmed between severe depressive symptoms and medication level such as the individual needing tablets or pumps (95\% CI $0.189-1.05, p 0.005$ and 95\% CI $0.52-$ $1.44, p$ 0.001) respectively. Other disease-related variables showed no significant correlation with depressive symptom levels.

Additional significant relationships were found in environment whereas increased moderate depressive symptoms were experienced by individuals residing in rural areas as opposed to those living in IDP camps or cities by 4 times (95\% CI $-0.30-0.01, p 0.04$ ), but no significant association was found between severe depression and the place of residence. The other independent variables (age, marital status, work, age at DX, period for blood transfusion, level of ferritin, complications) had no significant correlation with sever or moderate depressive symptoms.

\section{Discussion}

This study aimed to identify the prevalence of depression symptoms and socio-demographic characteristics associated with it among patients with moderate to severe thalassemia in the West Bank of Palestine.

The current study demonstrated that a majority $(78.5 \%)$ of the sample had moderate to severe depression per the Beck Depression Scale (55.8\% of the participants had severe depression while $22.7 \%$ had moderate depression). There are a variety of factors that may influence this finding. This could be attributed to the political conditions in Palestine for all Palestinians but may also be related to the unemployment rate for those with thalassemia, the inability to adequately participate in educational programs, the inability to marry in some cases as well as individual factors not addressed in the data.

In a previous study, Sabry and Salama (2009) found no thalassemia patient free from depression symptoms and demonstrated that depressive levels were significantly higher among individuals affected by thalassemia than the non-affected population [20]. This result concurs with Khurana's work, who found that most individuals with thalassemia reported at least moderate depression symptoms and low self-esteem [21]. In a sample of thalassemia patients in India, it was found that $30.8 \%$ had clinical depression and indicated that depression was the most common mental disorder among individuals with thalassemia in India [22]. All of these findings concurred with the results of the current study.

Factors associated with depressive symptoms among moderate to severe thalassemia patients in the current sample was gender with males having more significant 
Table 3 Generalized linear models for factors associated with minimal to mild compared with severe depression and for factors associated with minimal to mild compared with moderate depression among PWT

\begin{tabular}{|c|c|c|c|c|c|c|c|c|c|c|c|c|c|}
\hline \multicolumn{8}{|c|}{ Minimal to mild compared with severe depression among PWT } & \multicolumn{6}{|c|}{$\begin{array}{l}\text { Minimal to mild compared with moderate } \\
\text { depression among PWT }\end{array}$} \\
\hline & \multirow[t]{2}{*}{ v } & \multirow[t]{2}{*}{ B } & \multirow[t]{2}{*}{ SE } & \multirow[t]{2}{*}{ Chi } & \multicolumn{2}{|l|}{$95 \% \mathrm{Cl}$} & \multirow[t]{2}{*}{$P$} & \multirow[t]{2}{*}{ B } & \multirow[t]{2}{*}{ SE } & \multirow[t]{2}{*}{ Chi } & \multicolumn{2}{|l|}{$95 \% \mathrm{Cl}$} & \multirow[t]{2}{*}{$P$} \\
\hline & & & & & Lower & Upper & & & & & Lower & Upper & \\
\hline \multirow[t]{2}{*}{ Gender } & Male & 0.345 & 0.140 & 6.058 & 0.070 & 0.620 & 0.014 & 0.237 & 0.121 & 3.855 & 0.000 & 0.473 & 0.050 \\
\hline & Female & $0 a$ & & & & & & Oa & & & & & \\
\hline \multirow[t]{3}{*}{ Age $(Y)$} & $16-20$ & -0.158 & 0.189 & 0.697 & -0.529 & 0.213 & 0.404 & -0.185 & 0.141 & 1.736 & -0.461 & 0.090 & 0.188 \\
\hline & $21-25$ & 0.186 & 0.162 & 1.312 & -0.132 & 0.504 & 0.252 & -0.207 & 0.144 & 2.063 & -0.490 & 0.076 & 0.151 \\
\hline & $>25$ & Oa & & & & & & Oa & & & & & \\
\hline \multirow[t]{3}{*}{ Residency } & City & $\mathrm{Oa}$ & & & & & & $\mathrm{Oa}$ & & & & & \\
\hline & Village & 0.020 & 0.163 & 0.015 & -0.300 & 0.339 & 0.903 & 0.296 & 0.145 & 4.164 & -0.300 & 0.012 & 0.041 \\
\hline & IDP camp & 0.069 & 0.214 & 0.103 & -0.351 & 0.488 & 0.748 & 0.172 & 0.207 & 0.690 & -0.351 & -0.234 & 0.406 \\
\hline \multirow[t]{3}{*}{ Education } & Primary & 0.478 & 0.209 & 5.216 & 0.068 & 0.889 & 0.022 & 0.034 & 0.269 & 0.016 & -0.493 & 0.016 & 0.899 \\
\hline & Secondary & 0.275 & 0.148 & 3.452 & -0.015 & 0.564 & 0.063 & 0.021 & -0.015 & 0.029 & -0.220 & 0.029 & 0.866 \\
\hline & Diploma and higher & $\mathrm{Oa}$ & & & & & & $\mathrm{Oa}$ & & & & & \\
\hline \multirow[t]{3}{*}{ MS } & Single & -0.270 & 0.296 & 0.837 & -0.849 & 0.309 & 0.360 & -0.713 & 0.548 & 1.693 & -1.788 & 1.693 & 0.193 \\
\hline & Married & -0.518 & 0.354 & 2.141 & -1.211 & 0.176 & 0.143 & -0.847 & 0.565 & 2.247 & -1.954 & 2.247 & 0.134 \\
\hline & Divorced & Oa & & & & & & Oa & & & & & \\
\hline \multirow[t]{2}{*}{ Work } & Employed & -079 & -0.079 & 0.273 & -0.378 & 0.219 & 0.620 & -0.173 & 0.158 & 1.190 & -0.138 & 1.190 & 0.275 \\
\hline & unemployed & Oa & & & & & & Oa & & & & & \\
\hline \multirow[t]{2}{*}{ Monthly income US (\$) } & $<400$ & 0.703 & 0.703 & 18.401 & 0.382 & 1.025 & 0.001 & 0.165 & 0.136 & 1.473 & -0.102 & 1.473 & 0.225 \\
\hline & $>400$ & Oa & & & & & & Oa & & & & & \\
\hline \multirow[t]{2}{*}{ Age at DX } & $\leq 1$ year & -0.207 & 0.149 & 1.916 & -0.501 & 0.086 & 0.166 & -0.014 & 0.116 & 0.014 & -0.241 & 0.014 & 0.906 \\
\hline & $>1$ year & Oa & & & & & & $\mathrm{Oa}$ & & & & & \\
\hline \multirow[t]{2}{*}{ Period for BT } & Weekly & 0.191 & 0.163 & 1.373 & -0.128 & 0.510 & 0.241 & 0.092 & 0.134 & 0.470 & 0.355 & 0.470 & 0.493 \\
\hline & Monthly or more & Oa & & & & & & Oa & & & & & \\
\hline \multirow[t]{2}{*}{ Ferritin level } & Low & 0.301 & 0.157 & 3.661 & -0.007 & 0.609 & 0.056 & -0.022 & 0.125 & 0.030 & 0.224 & 0.030 & 0.863 \\
\hline & High & Oa & & & & & & $0 \mathrm{a}$ & & & & & \\
\hline \multirow[t]{3}{*}{ Medications } & Tablet & 0.621 & 0.221 & 7.917 & 0.188 & 1.054 & 0.005 & 0.190 & 0.158 & 1.453 & 0.500 & 1.453 & 0.228 \\
\hline & Pump & 0.979 & 0.233 & 17.726 & 0.523 & 1.435 & 0.001 & 0.264 & 0.219 & 1.449 & 0.694 & 1.449 & 0.229 \\
\hline & No need & Oa & & & & & & $0 \mathrm{a}$ & & & & & \\
\hline \multirow[t]{2}{*}{ Complications } & Face changes & -0.082 & 0.221 & 0.137 & -0.515 & 0.352 & 0.711 & 0.106 & 0.161 & 0.432 & 0.422 & 0.432 & 0.511 \\
\hline & $\begin{array}{l}\text { Splenomegaly and } \\
\text { hepatomegaly }\end{array}$ & Oa & & & & & & Oa & & & & & \\
\hline
\end{tabular}

$Y$ year, MS marital status, DX diagnose, $B T$ blood transfusions, $V$ variable, $B$ coefficient, SE standard error, $P W T$ patient with thalassemia, IDPC internally displaced people's camps

symptomology ( $p$ 0.014). Males in Palestine carry a high social expectation for marriage, economic success, education, and responsibility for the family, especially in rural areas were women are not commonly working outside of the home. Unemployment, lack of education, and increased sense of responsibility may factor into the experience of depression in this population of male patients. These results are in accordance to a study in Iran where Ghaffari found that depression among males was more than in females with thalassemia [23]. Some studies in non-health affected populations found that males were more prone to depression [24]. However, the study of Naderi and a study of Khodaei conducted in Iran, found no significant association between gender and mental health disorders such as depression $[25,26]$.

The currently study additionally revealed a significant association between severe depression symptoms and education level among individuals with thalassemia in the West Bank ( $p$ 0.022).

Adib-Hajbaghery found a statistically significant association between lower levels of education and depression symptoms in individuals with thalassemia. They maintained that the higher level of education including knowledge about thalassemia itself could assist individuals to 
accept and adapt to their symptoms while lower levels of education lead to misunderstanding, self-blame and low self-esteem [27]. One consideration that must be further explored is the correlation between intelligence quotation (IQ), intellectual disabilities, specific learning disabilities in thalassemia, or as a mediating factor in the relationship between the lack of education and depression.

Biswas et al. (2016) found that challenging economic conditions of participants was a particular burden in India with the high costs of medical treatment and high levels of unemployment for individuals with thalassemia leading to psychological problems [28]. A study of Karaman showed that $31.6 \%$ of thalassemia participants were unemployed, and $59.1 \%$ had a monthly income below the countries standard. All these studies' findings concur with the results of this study which indicated that economic challenges (especially for the poorest) were related to depressive symptoms [29].

The current sample data demonstrated a significant correlation between depressive symptoms and the need for thalassemia medications in both tablets and pump form ( $\mathrm{p}: 0.005,0.001)$ respectively. This might be attributed to the additional level of physical complications, limitations or the pain and discomfort of economic burden that results from recurrent treatments. Moussa reported that frequent subcutaneous injections with the pump for patients of diabetes mellitus was associated with depression [30]. In addition, Trachtenberg reported that $63 \%$ of the thalassemia patients in his sample had used oral medication $11 \%$ had used a combination, and $6 \%$ had used a slow subcutaneous infusion or portable pump machine. In that study, taking oral chelation was significantly associated with depression $(p 0.01)$ [31]. In Palestine, the area of residence (city, rural, IDP camps) determines a wide variety of socio-economic factors including economic resources, employment opportunities, access to education, crowding, social acceptance, a psychological stress, etc. [32]. In the current investigation, it was found that there was a significant association between depression and participants' place of living whereas living in the village (as opposed to a city or IDP camp) was associated with increased level of depression ( $p$ 0.01). Shaligram found that $75 \%$ of rural area thalassemia patients were vulnerable to depression [33]. This could be attributed to their access to medical care, difference in education level or ability to find employment as well as isolation from other's with similar disabilities and possibly increased level of discrimination in terms of social isolation, etc. Of further interest are the variables that did not predict depression in individuals affected by thalassemia which included marital status, employment status, period of blood transfusion, age, and disease complications.
The current study has several limitations which may provide the opportunity for future studies. The data in the study was based on self-report of thalassemia patients. Since many had limited education, it is unclear how well they understood the task or felt pressure to agree with interviewers' inquiries. Second, the demographic variables were limited and no other intellectual/ psychological measures were administered. Comorbidity with other psychological disorders and or general/ specific learning disabilities are unknown and unevaluated. The Beck Depression Inventory (BDI) alone was used with no other psychological measures included in our study such and limited social/economic information was included. Future studies that utilizing different mental health measures among patients with thalassemia in Palestine are needed. Additionally, only one study group of thalassemia patients was included in this study which limited the generalizability of the findings. Future studies examining the role of depression across demographic groups are needed. Lastly, calculation of the number of patients with chelators or deforoxamine was not added as it was not the main purpose of the study.

\section{Conclusions}

The prevalence of depression among individuals with thalassemia appears to be high and more prevalent than in non-affected individuals. Males, individuals with lower academic achievement, and lower levels of economic resources were found to be more vulnerable to depression. Individuals required to use medications such as tablet drugs and pump machines were also found to be of higher risk for developing depression symptoms.

These findings bring to light the need for screening, monitoring, and offering treatment interventions for individuals with thalassemia throughout the lifetime. Additionally, programs addressing obstacles and access to education, employment and psychological support for individuals affected by thalassemia may mitigate and alleviate the consequent depression over time.

Further studies of the chronology of symptoms across the lifespan would increase knowledge of critical factors (developmental and other) in the acquisition of depression symptoms. Lastly, investigation on the effects of depression on the course and outcome of thalassemia will be essential to support this potentially vulnerable population.

\section{Abbreviations}

Cl: Confident interval; IDP: Internally displaced people's camps; DX: Diagnose; TM: Thalassemia major; LDL: Low-density lipoprotein; TI: Thalassemia intermediate; BDI: Beck Depression Inventory; IQ: Intelligence quotation; PWT: Patient with thalassemia. 


\section{Acknowledgements}

An-Najah National University and Palestinian Ministry of Health are greatly acknowledged for their help and support to do this study.

\section{Authors' contributions}

All authors contributed to the study conception and design. Material preparation, data collection and analysis were performed by SM, AS, FM, and DB. The first draft of the manuscript was written by AS and all authors commented on previous versions of the manuscript. All authors read and approved the final manuscript.

\section{Funding \\ No fund}

\section{Availability of data and materials}

The datasets used and/or analyzed during the current study are available from the corresponding author on reasonable request.

\section{Declarations}

\section{Ethics approval and consent to participate}

All procedures performed in this study involving human participants were in accordance with the ethical standards of An-Najah National University's Research Ethics Board (Reference number 20/AP/0019) and the American Psychological Association (APA. 2010) and with the 2013 Helsinki Declaration. Informed consent was obtained from all participants.

\section{Consent for publication}

Not applicable

\section{Competing interests}

The authors declare that they have no competing interests.

\section{Author details}

${ }^{1}$ Faculty of Medicine and Health Sciences, Department of Biomedical Sciences, Public Health Division, An-Najah National University, P.O. Box 7, Nablus, Palestine. ${ }^{2}$ Psychology and Counseling Department, An-Najah National University, Nablus, Palestine. ${ }^{3}$ Nationalities Service Center, Philadelphia, USA.

Received: 30 Auqust 2021 Accepted: 20 November 2021

Published online: 07 January 2022

\section{References}

1. Shafie AA, Chhabra I, Wong J, Mohammed NS, Ibrahim HM, Alias H (2020) Health-related quality of life among children with transfusion-dependent thalassemia: a cross-sectional study in Malaysia. Health Qual Life Outcomes 18:141. https://doi.org/10.1186/s12955-020-01381-5

2. Old J, Harteveld CL, Traeger-Synodinos J, Petron M, Angastinniotis M, Galanello R (2012) Prevention of Thalassaemias and Other Haemoglobin Disorders: Volume 2: Laboratory Protocols, 2nd edn. Thalassaemia International Federation, Nicosia (Cyprus) Available from: https://www.ncbi. nlm.nih.gov/books/NBK190576/

3. Khairkhah F, Mahmoodi Nesheli H, Yahyaei AR, Khodabakhsh E, Husseini SR (2015) Evaluation of mental health and quality of life among $\beta$-thalassemia major patients. CJP 1(2):54-59

4. Needs T, Lynch DT (2018) Beta thalassemia. In: NCBI (National Center for Biotechnology Information) Bookshelf. StatPearls Publishing LLC https:// www.ncbi.nlm.nih.gov/books/NBK531481/. October 2, 2018. Accessed Nov 21

5. Galanello R, Origa R (2010) Beta-thalassemia. Orphanet J Rare Dis 5:11. https://doi.org/10.1186/1750-1172-5-11

6. Taher AT, Musallam KM, Cappellini MD, Weatherall DJ (2011) Optimal management of $\beta$ thalassaemia intermedia. Br J Haematol 152(5):512523. https://doi.org/10.1111/j.1365-2141.2010.08486.x

7. Thalassemia diagnosis and treatment, Mayo Clinic (2021). Accessed 28 Jan. Available from: https://www.mayoclinic.org/diseases-conditions/ thalassemia/diagnosis-treatment/drc-20355001.
8. Palestinian Ministry of Health (2016) Annual report. In: Palestinian Health Information Center (Ed.) (pp. 55, 113). Palestine

9. American National Institute of Mental Health [NIMH] (2020) Depression. Available from: https://www.nimh.nih.gov/about/index.shtml/. Accessed 25 Jan.

10. Sarkhel S (2009) Kaplan and Sadock's synopsis of psychiatry: behavioral sciences/clinical psychiatry, $10^{\text {th }}$ edition. Indian J Psychiatry 51(4):331

11. Chengappa KN, Kupfer DJ, Frank E, Houck PR, Grochocinski VJ, Cluss PA et al (2003) Relationship of birth cohort and early age at onset of illness in a bipolar disorder case registry. Am J Psychiatry 160(9):1636-1642. https://doi.org/10.1176/appi.ajp.160.9.1636 PMID: 12944339

12. Yahia S, El-Hadidy MA, El-Gilany AH, Anwar R, Darwish A, Mansour AK (2013) Predictors of anxiety and depression in Egyptian thalassemic patients: a single center study. Int J Hematol 97(5):604-609. https://doi. org/10.1007/s12185-

13. Maheri A, Sadeghi R, Shojaeizadeh D, Tol A, Yaseri M, Rohban A (2018) Depression, anxiety, and perceived social support among adults with beta-thalassemia major: cross-sectional study. Korean J Fam Med 39(2):101-107. https://doi.org/10.4082/kjfm.2018.39.2.101

14. Mednick L, Yu S, Trachtenberg F, Xu Y, Kleinert DA, Giardina PJ et al (2010) Symptoms of depression and anxiety in patients with thalassemia: prevalence and correlates in the thalassemia longitudinal cohort. Am J Hematol 85(10):802-805. https://doi.org/10.1002/ajh.21826

15. Maioli M, Pettinato S, Cherchi GM, Giraudi D, Pacifico A, Pupita G et al (1989) Plasma lipids in beta-thalassemia minor. Atherosclerosis 75(23):245-248. https://doi.org/10.1016/0021-9150(89)90182-2

16. PartonenT HJ, Virtamo J, Taylor PR, Lönnqvist J (1999) Association of low serum total cholesterol with major depression and suicide. Br J Psychiatry 175:259-262. https://doi.org/10.1192/bjp.175.3.259

17. Beck AT, Steer RA, Brown GK (1996) Manual for the Beck Depression Inventory-II. Psychological Corporation, San Antonio

18. Lee EH, Lee SJ, Hwang ST, Hong SH, Kim JH (2017) Reliability and validity of the Beck Depression Inventory-II among Korean adolescents. Psychiatry Investig 14(1):30-36. https://doi.org/10.4306/pi.2017.14.1.30

19. Alansari BM (2006) Internal consistency of an Arabic adaptation of the Beck Depression Inventory-II with college students in eighteen Arab countries. Soc Behav Personal 34(4):425-430. https://doi.org/10.2224/ sbp.2006.34.4.425

20. Sabry N, Salama KH (2009) Cognitive abilities, mood changes and adaptive functioning in children with $\beta$ thalassaemia. Curr Psychiatry 16(3):244-254

21. Khurana A, Katyal S, Marwaha RK (2006) Psychosocial burden in thalassemia. Indian J Pediatr 73(10):877-880. https://doi.org/10.1007/BF028 59278

22. Pradhan PV, Shah H, Rao P, Ashturkar D, Ghaisas P (2003) Psychopathology and self-esteem in chronic illness. Indian J Pediatr 70(2):135-138. https://doi.org/10.1007/BF02723739

23. Ghaffari Saravi V, Zarghmi M, Ebrahimi E (2004) The prevalence of depression in Thalassemic patients in the city of Sari. IJPCP 9(3):33-40

24. Beamish P, Patel P, da Silva T, Kaushalya D, Premawardhena A, Williams S et al (2016) Examining depression and quality of life in patients with thalassemia in Sri Lanka. Ann Global Health 82(3):551-552. https://doi. org/10.1016/j.aogh.2016.04.485

25. Naderi M, Hormozi MR, Ashrafi M, Emamdadi A (2012) Evaluation of mental health and related factors among patients with beta-thalassemia major in South East of Iran. Iran J Psychiatry 7(1):47-51

26. Khodai S, Karbakhsh M, Asasi N (2005) Psychosocial Status In Iranian Adolescents With Beta-Thalassaemia Major. Tehran Univ Med J 63(1):18-23 URL: http://tumj.tums.ac.ir/article-1-1047-en.html

27. Adib-Hajbaghery M, Ahmadi M, Poormansouri S (2015) Health related quality of life, depression, anxiety and stress in patients with beta-thalassemia Major. Iran J Pediatr Hematol Oncol 5(4):193-205

28. Biswas A, Sarkar K, Firdaus R, Saha K, Gupta D, Ghosh M et al (2016) Prevalence of anti-HCV, HbSAg, HIV among multi-transfused thalassemic individuals and their socio-economic background in Eastern India. Asian J Pharm Clin Res 9:314-318

29. Karaman A, Ben Naeem S, Ahmad T, Zainab S (2016) Psycho-social and economic impact of thalassemia major on patients' families. IMJ $8(1): 24-27$

30. Moussa MA, Alsaeid M, Abdella N, Refai TM, Al-Sheikh N, Gomez JE (2005) Social and psychological characteristics of Kuwaiti children and 
adolescents with type 1 diabetes. Soc Sci Med 60(8):1835-1844. https:// doi.org/10.1016/j.socscimed.2004.08.018

31. Trachtenberg FL, Mednick L, Kwiatkowski JL, Neufeld EJ, Haines D, Pakbaz $Z$ et al (2012) Thalassemia clinical research network. Beliefs about chelation among thalassemia patients. Health Qual Life Outcomes 7(10):148. https://doi.org/10.1186/1477-7525-10-148

32. Thalassemia Patients Friends Society (2014) Thalassemia Disease and Methods of Treatment [TPF]. Ramallah, Palestine

33. Shaligram D, Girimaji SC, Chaturvedi SK (2007) Psychological problems and quality of life in children with thalassemia. Indian J Pediatr 74(8):727730. https://doi.org/10.1007/s12098-007-0127-6

\section{Publisher's Note}

Springer Nature remains neutral with regard to jurisdictional claims in published maps and institutional affiliations.

\section{Submit your manuscript to a SpringerOpen ${ }^{\circ}$ journal and benefit from:}

- Convenient online submission

- Rigorous peer review

- Open access: articles freely available online

- High visibility within the field

- Retaining the copyright to your article

Submit your next manuscript at $\boldsymbol{\nabla}$ springeropen.com 